Thematic Article

\title{
New Paths to Online Teaching - How Can We Manage Knowledge Transfer and Make the Learning More Enjoyable?
}

\author{
András Benedek ${ }^{1}$ \\ Recommended citation: \\ Benedek, A. (2021). New paths to online teaching - How can we manage knowledge transfer and make the learning more \\ enjoyable? Central European Journal of Educational Research, 3(3), 55-62. https://doi.org/ \\ $10.37441 /$ cejer/2021/3/3/10015
}

\begin{abstract}
This study is based on the results from a national project initiative on digitalization, supported by methodological evidence from e-learning materials based on teachers' level of training for vocational education institutes. Looking for the new paths to online learning, we have been formulating the following question for almost a decade: How can we manage the transfer of knowledge and make learning more enjoyable at the same time? Our paper seeks a new method for content development and its application in vocational education and training (VET). This study recommends a kind of open framework. This framework's innovation, using open source content development as an approach to reforming teacher training for VET, is provided by a technical university with long-standing traditions (URL1). Moreover, the analysis of that innovation is also relevant from an international point of view, as the Hungarian VET system has undergone significant content transformation in the last decade. Our research group has undertaken developing the methodological training terms for complex school subjects and their educational results. By applying a new innovative concept, our objective was to renew vocational teacher training and practical training by creating and applying complex learning content units online.
\end{abstract}

Keywords: Vocational Education and Training (VET); open content; teacher training; online learning

\section{Introduction}

After the turn of the millennium, the search for new education solutions became the focus of social thinking and innovation. Thus, Colons and Halverson's questions on Rethinking Education in the Age of Technology are particularly timely: "How can we develop games to teach mathematical reasoning? How can we make learning technology available to more people? What tools can support people learning on their own?" (Colons et al., 2009: 9). Sadly, these questions are waiting for answers. Even the Pandemia crisis asked of educators: how can we manage knowledge transfer and make the learning more enjoyable?

Around 2010, the original aim of this research was developing and implementing new methodology for open learning content development, which is able to be used practically, in VET processes, evolving during student/teacher activities. Concerning the complex subject nature, new types of online info-communication technology (ICT) supported learning materials are elaborated and tested. The result is checked, and the research is evaluated in terms of the theoretical subjects of secondary vocational schools. Even using cloud services was

\footnotetext{
1 Budapest University of Technonolgy and Economics, Department of Technical Education; Budapest, Hungary; benedek.a@eik.bme.hu

The Open Content Development research group that, besides experienced and academic researchers, includes practitioners as well as students who are engaged in scientific student work and are attending their engineer and economist teacher evening courses while being present in school practice, was established in 2015 within the framework of the Department of Technical Education and the Teacher Training Centre of the Budapest University of Technology and Economics (BME) to implement a project focused on researching methods supporting learning, and initiated and financed by the Hungarian Academy of Sciences (HAS).
} 
an essential feature of the research given. Another critical question was how to make learning more exciting and enjoyable within the framework of the VET for weakly motivated learners.

According to the reform of vocational didactics (Nore, 2015), the rapid changes of VET demand answers concerning content and qualification development, and a new pedagogical spectrum in the online learning environment. These challenges have given rise to new issues like transforming rapidly changing vocational training content into effective learning and teaching resources, making learning more fun by increasing student learning activities, working within the relatively limited time frames. Thus, active learners are often involved constructively in the creation of open learning resource structures in both traditional and virtual learning environments.

In Hungary, VET and especially vocational school teachers and instructors traditionally play a complex role in organizing and reconstructing vocational training. As such, they demand continuously updated training content and teaching methods. This vocational training innovation process should be continuously adapted to technical, technological and economic changes. ICT developments and new online solutions have had a great impact on education in recent decades. Changes that initially seemed to be mere technological advancements now touch all educational methods and content as regards its modernization.

This past decade, regarding the theory of learning levels, the connective approach (Siemens, 2005) played an increasingly important role, while also transforming practice. Even though it has not gone undisputed, this theory can be said to have started significant movements towards innovation. "...in the case of educational resources, the roles of institutions and their employees may differ significantly from one institution to another. Mindful of this, a major charity is funding research into how different institutions interpret open educational resources (OERs), specifically in relation to the co-creation of knowledge" (Bell, 2011: 108).

The life of educational and training institutes is being transformed by OERs (open content development) and e-learning applications - and not just at a methodological level; the perspectives and operations of these institutions are also changing, and the quality of teaching in higher education is undergoing a renewal process (Beetham et al., 2019). More and more educational institutes are making higher education more flexible and easy to access by giving thousands students the opportunity to opt for open courses. Centres of learning such as the Open University in Milton Keynes (UK), the FernUniversität in Hagen (Germany), and the Universitat Oberta de Catalunya in Barcelona (Spain) boast many decades of successful track records, still it can be said that they are only now considering online teaching and learning systems.

Thanks to ICT tools, making modern learning methods have become generic, while network communications have typically made up the innovative dimension of learning. The significant initiatives - for example, the D-Transform project (Transforming Universities for the Digital Age) within the framework of the EU Erasmus+ Programme - analyse how activities assuming continuous interaction affect learning and the transfer of knowledge in the digital environment. Following these tendencies, In the last few years, different projects have intensively studied Hungary in respect to open education. It can be assumed that between absolute enthusiasm and absolute rejection, multitudinous institutional strategies are taking shape. Thus, we will be introducing the new e-learning teaching forms using ICT tools online, and open content's development and application by VET teachers.

\section{From theory to practice}

When our methodological proposal was accepted in 2016, we, in line with the unique features of the Hungarian VET system, undertook developing methodological training in complex school subjects. Our objective: to modernize the methodology by applying our new methodological concept. We applied it in vocational teacher training and practical training by creating and using complex units of educational content, becoming somewhat typical in today's school vocational education (Gessler et al., 2015). Realizing this tendency, we oriented our methodological development program to be task-focused on micro content based learning units in vocational teacher training and further practical education.

One task we successfully completed was to provide methodological support for vocational teacher training in technical and economic fields. The various parts of this completed task were development of training and content used to qualify VET instructors, and the development needful for the practical field training of teachers enrolled. Both result from the joint work of the research and service network of teacher training institutions and the extension of the national network of cooperating VET and higher educational institutions. During the project period, this endeavour of ours was verified by the fundamental transformation of Hungarian VET and a sixty percent reduction in the number of primary vocations (currently, the number being taught in vocational schools 
is 174). The new subject modules introduced in vocational teacher training (Theory of Education, System Theory) put the testing into practice. By 2021, a new model was tested in 12 pilot VET schools and integrated into our vocational teacher training program. The main components of the Open Content Development model contained the following main elements seen in Figure 1.

Figure 1. The main components of OCD model

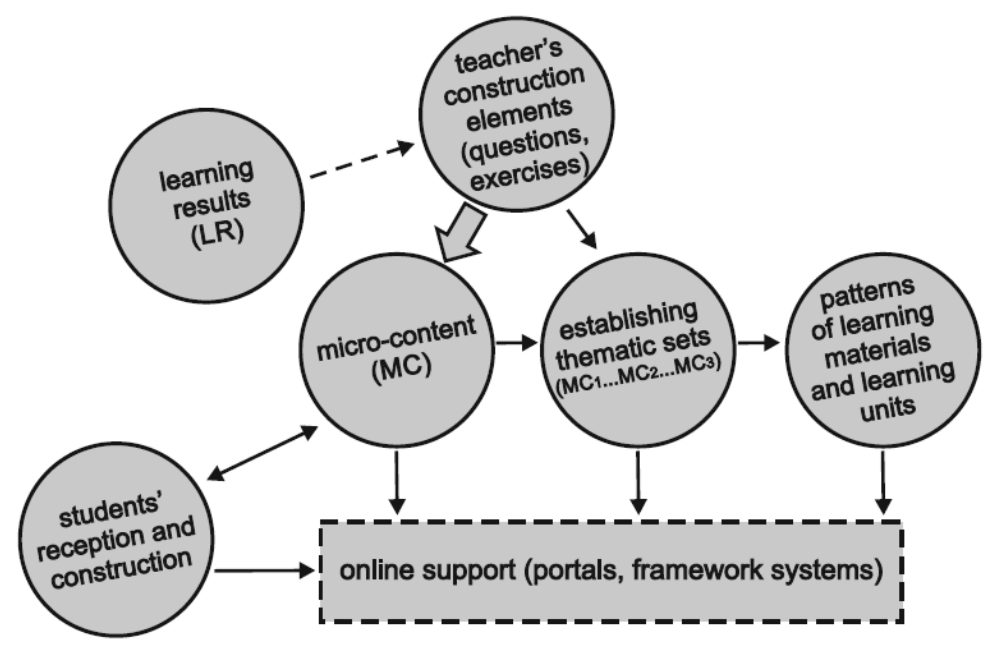

Concerning international tendencies, VET recognised that after the economic drop of the latest decade, educational innovation spun up in prosperous economies, namely leaders in technological development (Germany, Japan, South Korea, the UK or the USA). These systems survived the crisis due to an intense and goal-oriented process including the renewal of education and vocational training. Online structures and cooperation were took increasingly decisive roles. Attitudes formed about technical culture, VET systems and their innerworkings, and the applied methods were affected. Therefore, at the outset, we substantiated and debated the basic concept of our research, only later moving to the detailed program on the given topic. This was provided by documented analysis of the professional literature. During this process, it was proved and verified that in content development a fundamental trend was forming, with construction of new teaching resources, and elaboration on and rapid introduction of new-type electronic learning content. Besides vindicating interdisciplinary attitudes, the ICT environment of education is gaining more ground. VET, built on traditional and inflexible subject systems, is now seeking more flexible solutions concerning content and organizational frameworks.

In 2019-2020, all this initiated a complete renewal of content and a reorganization of VET institutions (centres and affiliated schools). This created (both due to and independent from the pandemic) the constraint and possibility of methodological change. The development of VET became a general priority, demand for methodological modernization promising significant innovation by using the project results. Currently, due to the speed of transformation, this process is under administrative control dominated by top-down, centralized development, and content development. Local innovations offer new possibilities since the project results reflect diverse methodological demand.

Over the last decade and throughout the pandemic, it has become a development trend to provide mass access to educational content through the internet, brining on the need for innovation. Thus, our goal became to involve interested students/teachers in putting together open access learning materials, and it seemed to be quite innovative. Another possibility for innovation appeared in the form of cloud services, ensuring the background storage capacity necessary for the process to succeed.

Though this be the topic: higher education initiations according to more widespread Mass Open Online Courses (MOOCs) and LMS (Learning Management System), the application of educational frameworks in VET is justified by the high number of participants. School processes, content development, learning resource development, practical result implementation, teacher preparation, vocational teacher training, and further training have become factors determining the quality and dynamics of innovation. By using the new methodology, the participating vocational teachers played an influential multiplier role in the highlighted development programs and local innovation implemented at the institutional level. During the project period, domestic regulatory frameworks improved. The result: new conditions (regarding planning of the pedagogical 
process; supporting, organizing and directing learning; evaluating educational processes and pupils; and measuring methodological and vocational knowledge) appeared amongst the qualification and output requirements of vocational teacher training programs.

Within the vocational teacher training program, new subject constructions were introduced allowing for collaborative teaching online via the assembly of micro content. In parallel with this, the new complex methodology of the other teacher training program was elaborated, tested, licensed and put into practice. Network as an approach and as a conceptual factor has become the new institutional framework of methodological developments and the organization of work contacts. Its importance in creating the development model of local innovation was of strategic significance. As a result of the organizational transformation, the domestic VET system became better integrated and economically scaled. At the same time, we experienced the fluctuation of vocational teachers and institutional leaders during the project. In several cases this caused personal changes at the practical level. In spite of all this, a more comprehensive application of open learning resource development is likely to become one of the effective models used in projects implemented. This would be accomplished with a relatively low budget and developments being consciously built upon the resources of local innovation.

In the second part of the research period, we published the empirical results showing experiences with the methodological elements, mainly the introduction of learning resource development based on micro content, doing so primarily in foreign language papers.

The construction system of learning units - micro content offers a framework for local methodological development. Our project was built consciously on the worldwide spread of content management in VET systems, which offered a new innovative environment for continuously renewing the teaching and learning content. This innovation is taking open educational content development into a well-known technical university's vocational teacher training program, introducing it as one of the approaches to renewing teacher training. The methodological speciality of the research was model creation based on theoretical analyses, which served as the ground for the implementation of learning resource development tasks with the involvement of engineer and economist teacher students (Benedek et al., 2016). In this process, during the construction of the online teaching resources, they implemented professional tasks that led to creating the the content management model. The survey and interviews made with these students and the management of the micro content developed by the students can be considered a new method. It was essential to involve the students (future vocational teachers) in the open learning resource development process and equip them with methodological knowledge suitable for the permanent development of active learning (with community content development elements). We introduced our model at several significant international conferences. We disseminated it primarily in the volumes issued by the European Research Network in Vocational Education and Training (VETNET) as an international collaborative forum to implement project ideas and results. It was founded in 1996 as one of the research networks of the European Education Association (EERA). After the European Conference on Educational Research (ECER) 2017-2019 conferences, this network discussed the presented open learning resource development process OCD (Open Content Development).

In the spring of 2020, without preliminaries, we quickly applied the open-content development method to support collaborative asynchronous learning directly and with a thematic focus in vocational teacher training and distance education. A more significant set of micro content (47) was developed within the course titled the pedagogical issues of sustainable development, which held special significance in the current situation, offering the opportunity to construct and evaluate cooperatively within the frameworks of student activities. The global pedagogical problem jointly identified with the students, which can be considered a complex learning unit in VET, illustrated the practicability of open content development. We presented the action research results at an international online conference (26th Annual Conference of the International Sustainable Development Research Society, Budapest, 15-17 July 2020), which allowed us to have the research results published relatively quickly (Benedek, 2020a). Afterwards, in autumn of 2020, to do further research on the dynamics of content development, the vocational teacher students were taught the methodological elements of the micro content-based construction process within the confines of similar action research and in terms of another complex topic (digital learning).

Since methodological developments have borne great significance during the latter months, we strived to hold lectures that, in line with the peculiarities of the current situation in VET, introduced the new construction solutions offered by open content development and promoted their spread in practical work. In May 2020, we undertook the presentation of the opening lectures at two major conferences: the Hungarian Conference on 
Educational Research (HUCER) conference ' The paradigm-changing educational challenges of the digital era' and the Education-Information Technology-Pedagogy digital conference - "Hybrid: Curse or Opportunity?"

Within the project frames, we consciously strove to provide the infrastructural conditions of online communication and networking via cloud services. As a result, in the second part of the project, several schools were able to connect to the cloud services provided by the MTA, which made operation of the content development databases and platforms demanding significant memory capacities much easier. During the pandemic, bandwidth was a constant issue. Difficulties with content memory capacity and uploading that arose during online teaching and learning were added thorns in the sides of institutions. Therefore, the temporary period's main objective was to connect our services to cloud technologies and platforms already developed for mobile communication tools. To achieve this, we proposed developing and introducing new cloud service integration solutions and methodological support into institutional practice within the bounds of a new and complex project.

\section{The impacts of the pandemic exigency and our reactions}

In 2016, joining the work of the Subject Pedagogy Research Program of the Hungarian Academy of Science allowed our research group to deal with digital education issues to build multidisciplinary approaches and contacts with researchers examining complex problems. The situation had evolved in March 2020, probably valorizing this feature since atypical learning and training, which are more common in VET, faced the challenges and problems the researchers knew at the beginning of the pandemic. The cancellation of the research group's immediate, upcoming meetings and events caused considerable setbacks. However, the general practice of online communication did not limit the typical activities of the researchers. Nevertheless, the working order of school instruction has changed significantly and, in several cases this past year, has had a significant impact on our activities as well.

However, the inevitable switching over to digital schoolwork proved our point that problems are getting more complicated. Their management cannot be successful utilizing just one discipline. Therefore, we need to apply more complex and open approaches. Building on the available research background, our methodological proposals in educational development were characterized by interdisciplinarity, complexity, systemic approach, and openness in the spirit of which we shared the professional opportunities offered by the resources at our disposal (our web page, papers, online workshop series and new development platforms). In the course of the last year, in the closing phase of the project, the core elements of our activities have been the innovative support of VET and teacher training, and the dissemination of practical methodological results. We met a publishing goal when we put out a study volume in October 2020, which included the results of and references to the research and development along with our methodological proposals (Benedek, 2020b). Extending our series of papers launched last year, in the bulletin of the Open Content Development Research Group of the MTA-BME (URL1), we have published another 4-5 methodological proposals on higher educational teacher training, presenting processes involving the development environment and its application in putting together open content. According to the principle of open access, we designed and finalized the tools, software and online platforms (MIKROPEDIA, Sysbook) and mobile app processes that would make content development in VET available for the wider professional public.

Maximizing the possibilities of online dissemination, we attended the most significant Hungarian Educational Conference for the fourth time, where we organized two independent symposiums. In the autumn of 2020, we introduced the final volume of the project to the broader professional public at an online event extending over the sizes of a workshop conference. In line with our original plans and within the new online frameworks, we connected to the program of the 9th Budapest Visual Learning International Conference organized by our research group, the BME and the Corvinus University with the active participation of the BME Visual Learning Lab that had been forming the conceptual frames of our researches for a decade (Benedek, 2020c). Building on the experiences gained from our previous courses and applying new online collaborative methods (Digital Pedagogy, Educational Theory and System Theory), we integrated the content development of MA teacher training into the BME GTK Moodle framework system that was renewed in 2020-2021. We have made the experiences gained about the application part of the general practice in the methodological modernization of the teacher training. In order to have our methodological development results utilized in practice as widely as possible, we organized our teachers' further training program (OCD training) authorized by the Educational Authority in new VET centres online and to strengthen their future sustainability and broader use. 


\section{Introducing the project results to the teacher training}

Vocational teacher training content was modernized by renewing and integrating the output requirements and subject system. The new system into which they were integrated supported electronic learning. Also, new courses (Theory of Education and System Theory) were introduced. These made it possible to learn how to develop content cooperatively online, how to organize micro content related to learning units, and how to use the methods and techniques relevant in this field. These structures were created and introduced into economist and engineer-teacher training, and the project's documentation allows for long-term, sustainable methodological development.

In vocational teacher training, specifically when online during the pandemic, some thematic constructions (sustainability in pedagogy or digitalization in the education) using micro content-based solutions (for example, the Micropedia) that we proposed to apply in a broader range in school practice were introduced. Among the many new digital repositories, this system is a state-of-the-art cloud service based on the principle of open access, a much-supported development system for teacher-educated students and educators in pilot schools. In line with the characteristics of vocational teacher training, since 2018, each of the graduating teachers (127 persons) has learned this technique and can use it in local content innovation.

According to our original goals, in 2017, we elaborated, and the Educational Authority certified the methodological training program that offered the possibility for vocational teachers to acquire the new complex methodology. We introduced the methodological process supporting online collaborative learning and creating the related micro content at each of the schools involved in the pilot network, and we also held the training. Within teachers' further study, in 2019-2020, the program was applied at several VET centres, and the feedback was positive. However, during the pandemic, the specialist training activity considerably decreased, which was a result of the fact that the concerned vocational teachers were withdrawn from the teacher staff (public employee status), and their participation in future training systems within the VET structure had not yet been fixed. Nevertheless, according to the existing professional references, it will be possible to continue the other training program and continue its development in line with the new system's demands.

In addition to our continuously maintained website, the project results are promoted online by several other platforms supporting the development of micro content-based learning units (SysBook - URL2, Micropedia - URL3). Furthermore, in the project's final year, the mobile application (McApp) promoting pupils' activity during online collaborative development work has also been made ready. Regarding the dissemination of the results, the fact that our bulletin series' (Papers of the MTA-BME Open Content Development Research Group - W1) first volumes were published in print, while due to COVID-19 the later ones appeared online, and are also available on our webpage, bears great importance. Finally, according to our original projects plan, in October 2020, the edited volume summarizing the project process and the main results of the first period of the research was presented.

During a later phase, by using the cloud services in a complex way, we strove to make it easier in the future for the archiving system operated by the Micropedia platform to be able to professionally and generally analyse as well as methodologically evaluate micro content created by teachers and students during the development stage. To do so, the use of the electronic badges is necessary, such that are used in micro-crediting processes on an international scale. This would mean considerable motivation for teachers and students joining content development. This also represents one of the essential possibilities to further develop the project.

\section{Conclusions}

Our research sought to contribute primarily to the modernization of the unique methodology of domestic VET and the implementation of innovative technics in learning content development by renewing the online collaborative methods apt to be used in teacher training and teaching practice. This objective was achieved in the first part of the project by creating and piloting the theoretical model and its discussion at the international professional fora. In parallel with the theoretical researches, the process connecting the theoretical model was integrated into the general methodology prep course of vocational teachers. The construction of micro contentbased learning units became applied amidst online learning challenges, which offered a flexible tool for the highly diverse VET content development that had accelerated exactly during the previous years.

During the project period, the structure and content system of domestic VET considerably changed; these changes formed the frameworks of applying the particular methodology in a complex (and preferable) way; however, the extremely rapid changes, especially the impacts of the pandemic measures during the latest year, strongly limited the mass expansion of the new methodology. Though the applied methods of open content 
development can be used in school practice with outstanding success, owing to the dynamic transformation of the educational system directed by halfway measures and the crisis caused by the pandemic, the innovation transfer slowed down at a rate higher than expected. So it requires further endeavours and initiations.

It is undoubted and must be taken as a fact in terms of the next research-development phase that the description and debate of theoretical results of the project and the open content development model at the international expert fora were implemented during the project. We introduced the project results in the three first volumes of the series published by the European educational researchers' VETNET network. Furthermore, we presented the implemented development and our empirical results at several significant international conferences, lectures, and publications. The publication activities connecting to the measurement and evaluation of the empiric results and applied methods have been launched, several paper drafts and initiations are being prepared. To assure the sustainability of the project results and the work done, it is reasonable that despite the secession of VET from the public education system be carried out. The electronic solutions managing the use of mobile communication tools and cloud services and the evaluation and analysis of the learning resource units created via collaborative processes and transmitted through network structures be applied later in the complex methodological research. These results and further dissemination may act as considerable innovation motivation and support for vocational teacher training, further training, and the broader educational practice.

One of the main tasks of the project's final phase is to broaden the implementation process and put the results into practice. New forms of professional publicity provide a communication framework for this: workshops, innovation programs, training forums, and dialogues with those actively involved in content development, from which new development plans and programs can be developed.

Acknowledgments: We thank Johnathan Dabney for the English language editing.

\section{References}

Beetham, H., \& Sharpe, R. (Eds.) (2019). Rethinking Pedagogy for a Digital Age: Designing for 21st Century Learning. New York: Routledge.

Bell, F. (2011). Connectivism. Its place in theory-informed research and innovation in technology-enabled learning. The International Review of Research in Open and Distance Learning, 12(3), 98-118.

Benedek, A. (2016). Sysbook as a visual learning frame. In Benedek, A. \& Veszelszki, Á. (Eds.), In the Beginning was the Image: The Omnipresence of Pictures: Time, Truth, Tradition. (Series Visual Learning; 6., pp. 161-170), Peter Lang Internationaler Verlag der Wissenschaften. https://doi.org/ 10.3726/b10396

Benedek, A., \& Horváth Cz., J. (2016). Case Studies in Teaching Systems Thinking. IFAC-PapersOnLine, 49, $286-290$. https://doi.org/10.1016/j.ifacol.2016.07.191

Benedek, A. (2020a). On-line Collaborative Learning Approach to SDGs in the Pedagogy Studies. In Gy. Zilahy (Eds.), Sustainability in Transforming Societies: Proceedings of the 26th Annual Conference of the International Sustainable Development Research Society. Faculty of Economic and Social Sciences, Budapest University of Technology and Economics (pp. 327-335). ISBN: 978-963-421-812-8

Benedek, A. (Eds.) (2020b). Új módszerek a szakképzésben - Kollaboratív online tartalomfejlesztés, MTA-BME Nyitott Tananyagfejlesztés Kutatócsoport. ISBN: 978-963-508-949-9

Benedek, A. (2020c). Visual Learning as an Opportunity and Compulsion for Innovation in the Period of Pandemic. In P. Aczél, A. Benedek, \& K. Nyíri (Eds.), How Images Behave. Hungarian Academy of Sciences, Budapest University of Technology and Economics (pp. 215-219). ISBN 978-963-421-841-8

Colons, A., \& Halverson, R. (2009). Rethinking Education in the Age of Technology. Teacher College Press. https://doi.org/10.1007/s11423-010-9159-0

Gessler, M., \& Moreno Herrera, L. (2015). Vocational Didactics: Core Assumptions and Approaches from Denmark, Germany, Norway, Spain and Sweden. International Journal for Research in Vocational Education and Training, 2(3), 152-160. https://doi.org/10.13152/IJRVET.2.3.1

Nore, H. (2015). Re-Contextualizing Vocational Didactics in Norwegian Vocational Education and Training. International Journal for Research in Vocational Education and Training, 2(3), 182-194. https://doi.org/10.13152/IJRVET.2.3.4

Horváth, Cz., J (2016). Micro content Generation Framework as a Learning Innovation. In A. Benedek \& Á. Veszelszki (Eds.), In the Beginning was the Image: The Omnipresence of Pictures: Time, Truth, Tradition. Series Visual Learning; (6., pp. 171-181). Peter Lang Internationaler Verlag der Wissenschaften. https://doi.org/10.3726/b10396

Siemens, G. (2004). Connectivism: A Learning Theory for the Digital Age. International Journal of Instructional Technology and Distance Learning, 2, 3-10. 
Sik, D. (2018). Introduction and Implementation of a Multi-leveled E-learning Environment Based on the Open Content Development Model Principles. In M. Auer, D. Guralnick \& I. Simonics (Eds.), Teaching and Learning in a Digital World. ICL 2017. Advances in Intelligent Systems and Computing (pp. 64-70). Springer. https://doi.org/10.1007/9783-319-73204-6_9

URL1: Retrieved September 25, 2021, from from www.ocd.bme.hu

URL2: Retrieved September 25, 2021, from sysbook.sztaki.hu

URL3: Retrieved September 25, 2021, from https://mikrotartalom.hu

(C) 2021 by the authors. Submitted for possible open access publication under the terms and conditions of the Creative Commons Attribution (CC BY) license (http://creativecommons.org/licenses/by/4.0/). 